\title{
LESTER J. UNGER, M. D.
}

\section{In Memoriam}

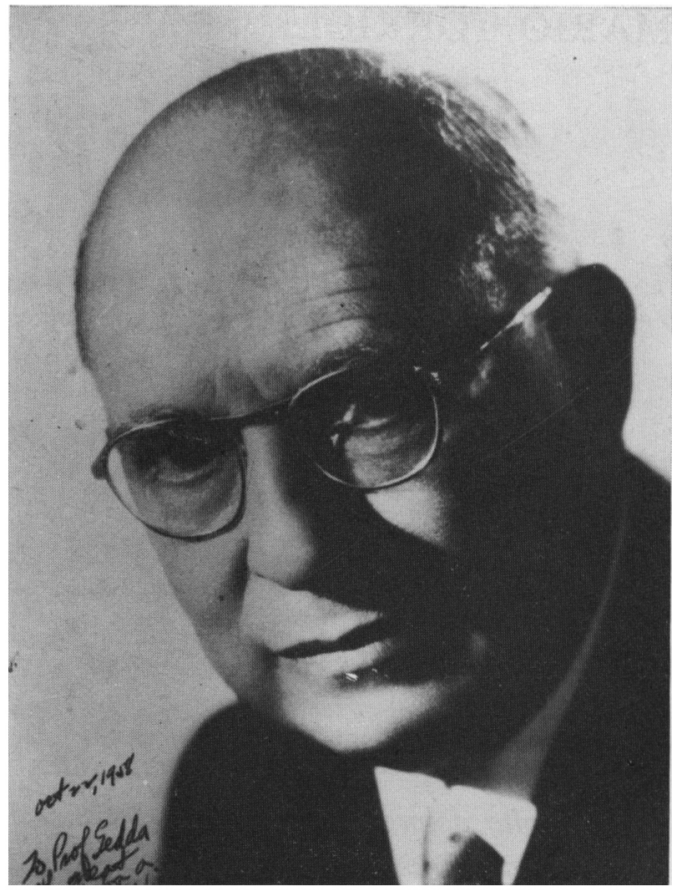

A faithful friend of our Journal and of the Mendel Institute, Dr. Lester J. Unger, has left us.

His warm, enthusiastic, active cooperation ranged from authorship of scientific papers to assistance in providing rare antisera or testing blood samples and many other freely given services.

Dr. Unger's annual visits to Rome were welcome occasions for us to renew our friendship and for him to share his knowledge with the students and staff at the Mendel Institute.

He was a member of the Advisory Board of this Journal and Consultant for Immunohematology to the Mendel Institute.

We all join with his family and friends in paying a heartfelt tribute to his memory.

\section{LUIGI GEDDA}

Acta Genet. Med. Gemellol. (1975), 24: 185 